\title{
Genetic characterization of cassava (Manihot esculenta Crantz) genotypes using agro-morphological and single nucleotide polymorphism markers
}

\author{
Kumba Y. Karim ${ }^{1,3} \cdot$ Beatrice Ifie $^{3} \cdot$ Daniel Dzidzienyo $^{3} \cdot$ Eric Y. Danquah $^{3}$. \\ Essie T. Blay ${ }^{3} \cdot$ Jim B. A. Whyte ${ }^{2} \cdot$ Peter Kulakow $^{2} \cdot$ Ismail Rabbi $^{2}$. \\ Elizabeth Parkes $^{2} \cdot$ Lucky Omoigui $^{2} \cdot$ Prince E. Norman $^{1,3}$ (I) $\cdot$ Peter Iluebbey $^{2}$
}

Received: 19 August 2019/Revised: 15 November 2019/Accepted: 24 November 2019/Published online: 23 December 2019

(C) The Author(s) 2019

\begin{abstract}
Dearth of information on extent of genetic variability in cassava limits the genetic improvement of cassava genotypes in Sierra Leone. The aim of this study was to assess the genetic diversity and relationships within 102 cassava genotypes using agro-morphological and single nucleotide polymorphism markers. Morphological classification based on qualitative traits categorized the germplasm into five different groups, whereas the quantitative trait set had four groups. The SNP markers classified the germplasm into three main cluster groups. A total of seven principal components (PCs) in the qualitative and four PCs in the quantitative trait sets accounted for $79.03 \%$ and $72.30 \%$ of the total genetic variation, respectively. Significant and positive correlations were observed between average yield per plant and harvest index $\left(r=0.76^{* * *}\right)$, number of storage roots per plant and harvest index $\left(r=0.33^{*}\right)$, height at first branching and harvest index $\left(0.26^{*}\right)$, number of storage roots per plant and average yield per plant $\left(\mathrm{r}=0.58^{*}\right)$, height at first branching and average yield per plant $(r=0.24 *)$, length of leaf lobe and petiole length $\left(r=0.38^{*}\right)$, number of leaf lobe and petiole length $\left(r=0.31^{*}\right)$, width of leaf lobe and length of leaf lobe $\left(r=0.36^{*}\right)$, number of leaf lobe and length of leaf lobe $\left(r=0.43^{*}\right)$, starch content and dry matter content
\end{abstract}

Prince E. Norman

penorman2008@yahoo.com

1 Sierra Leone Agricultural Research Institute, Tower Hill, Freetown PMB 1313, Sierra Leone

2 International Institute of Tropical Agriculture, Ibadan PMB 5320, Nigeria

3 West Africa Centre for Crop Improvement, College of Basic and Applied Sciences, University of Ghana, P.O. Box LG 30, Legon, Accra, Greater Accra, Ghana $\left(\mathrm{r}=0.99^{* * *}\right)$, number of leaf lobe and root dry matter $\left(\mathrm{r}=0.30^{*}\right)$, number of leaf lobe and starch content $\left(r=0.28^{*}\right)$, and height at first branching and plant height $\left(\mathrm{r}=0.45^{* *}\right)$. Findings are useful for conservation, management, short term recommendation for release and genetic improvement of the crop.

Keywords Cassava - Genetic diversity - Morphological traits $\cdot$ SNP markers

\section{Introduction}

Cassava (Manihot esculenta Crantz) is a very important root crop, containing high carbohydrate levels, used for human consumption, animal feed and industrial applications (Sánchez et al. 2009). The starchy storage roots of cassava have become the most important source of dietary energy in sub-Saharan Africa (SSA) as they provide more returns per unit of input than any other staple crop (Fregene et al. 2000; Scott et al. 2000; Nassar 2005). Cassava is a hardy plant that survives in poor soils with low fertility, relatively producing higher yields than other root and tuber crops (Temegne et al. 2015). However, cassava genotypes respond differently to diverse environmental (soil, climate) and biotic factors (Dixon et al. 2002).

In Sierra Leone, dearth of information on the extent of genetic variation within the breeding population of cassava limits the development of superior cassava genotypes. Determination of the genetic variation in breeding population facilitates identification of useful genetic divergence imperative for cassava population improvement. Genetic divergence in breeding population is evaluated by genetic markers (Andrade et al. 2017). Genetic markers such as agro-morphological markers had been used frequently in 
preliminary studies because they are fast and easy approach for assessing the extent of diversity among germplasm (Asare et al. 2011). Some of these morphological traits revealed the true diversity as perceived by farmers (Mckey et al. 2001; Pinton and Emperaire 2001). Elias et al. (2001) also reported that morphological traits have a heritable genetic variation. As knowledge in scientific research progressed, molecular markers were noted to unravel the genetic constitution and significance of traits through DNA fingerprinting, gene link detection, identification of genotypes, gene introgression, germplasm characterization, phylogenetic analysis, and indirect selection of agronomic traits (Souza 2015; Andrade et al. 2017). Such knowledge underpins the use of appropriate and reliable agro-morphological descriptor and molecular markers for the evaluation of genetic diversity (Fukuda and Guevara 1998).

Quantitative and qualitative morphological traits have been used for systematic identification of genotypes, species and genera of some crops (Smykal et al. 2008). Qualitative traits are usually controlled by few genes with major effects. These traits are easily observable, thereby making differentiation and identification of genotype easier. Conversely, quantitative traits are controlled by many minor genes with complex inheritance. These traits are more affected by environmental effects and developmental stage of the crop.

Genetic diversity studies using morphological traits alone are sometimes limited by the environment and genotype by environment interaction effects (Collard et al. 2005). These limitations may not permit the accurate detection of duplicates by morphological classification technique alone. Collard et al. (2005) reported that the use of molecular markers may permit the detection of genetic differences among closely related genotypes. Characterization of accessions may, therefore, be more reliable if molecular markers are closely associated with morphological traits. Various DNA markers have been utilized to assess genetic diversity in cassava germplasm (Okogbenin et al. 2012). These include restriction fragment length polymorphism (RFLPs) (Beeching et al. 1993), random amplified polymorphic DNA (RAPDs) (da Silva et al. 2015), amplified fragment length polymorphism (AFLP) (Fregene et al. 2000), simple sequence repeats (SSRs) (Asare et al. 2011) and single nucleotide polymorphism (SNP) markers (Kawuki et al. 2009). Of the above marker systems, SSR and SNP markers are among competitive markers for diversity studies. However, microsatellites may be limited by the presence of stutter bands that produce quasi-scoring in ladders lacking prominent bands thereby making scoring difficult (Park et al. 2009) and poor transferability across species (Grattapaglia and Kirst 2008). Single nucleotide polymorphisms are more easily assayed per locus compared to microsatellites. The SNPs are the most abundant marker system in plant, animal, and microorganism genomes and are considered as the new generation molecular marker for various applications. The SNPs are useful in detecting and distinguishing specific genetic variations even in a low diversity species (Ferri et al. 2010). The use of SNPs has accelerated the pace of genetic diversity research and gains in selection rather than using the conventional technique alone. Thus, the objective of the present study was to assess the genetic diversity and relationships within cassava germplasm using agro-morphological and single nucleotide polymorphism markers.

\section{Materials and methods}

\section{Plant material, experimental design and plot layout}

The trials were established in-field at the Njala Agricultural Research Centre (NARC) experimental site, southern Sierra Leone in the 2015/2016 cropping season. Njala is situated at an elevation of $50 \mathrm{~m}$ above sea level, $8^{\circ} 06^{\prime} \mathrm{N}$ latitude and $12^{\circ} 06^{\prime} \mathrm{W}$ longitude. A total of 102 cassava genotypes comprising 82 white and 20 yellow accessions were evaluated to determine the extent of genetic diversity within the breeding population (Table 1). The experiment was laid out in a $6 \times 17$ alpha lattice design with three replications. Stem cuttings measuring $30 \mathrm{~cm}$ in length each were planted on the crest of ridges at $1 \times 1 \mathrm{~m}$ spatial arrangement. No fertilizer or herbicide was applied. Hand weeding was done when necessary.

\section{Agro-morphological data collection}

A total of 22 agro-morphological traits comprising 11 quantitative and 11 qualitative traits were evaluated (Table 2) based on the agro-morphological descriptor of cassava described by Fukuda et al. (2010).

Harvest index (HI) was calculated at harvest as the ratio of fresh root yield to the total fresh biomass (weight of roots and weight of above ground biomass).

Starch extraction was done at harvest using a method described by Benesi (2005).

Starch content was calculated as:

Starch content $(\%)=\frac{\mathrm{DSW}}{\mathrm{FM}} \times 100$

where DSW is the weight of dried starch and FM is the weight of fresh tuber.

Root dry matter content (RDMC) determination was done at harvest by selecting three representative roots from the bulk of roots harvested from 5 plants. Cassava roots were washed and shredded into pieces. A standard measure of $100 \mathrm{~g}$ weight of the fresh samples was taken and oven 
Table 1 Storage root flesh attributes of 102 cassava genotypes used for the genetic characterization study

\begin{tabular}{|c|c|c|c|c|c|}
\hline Genotype & Storage root flesh color & Genotype & Storage root flesh color & Genotype & Storage root flesh color \\
\hline TR0991 & White & TR0188 & White & TR1523 & White \\
\hline TR1827 & White & TR1782 & White & TR0218 & White \\
\hline TR1036 & White & TR1069 & White & TR0043 & White \\
\hline TR1013 & White & TR0075 & White & SLICASS6 & White \\
\hline TR0038 & White & TR0575 & White & TR0142 & White \\
\hline TR0768 & White & TR1696 & White & TR0813 & White \\
\hline TR0519 & White & TR0127 & White & TR0971 & White \\
\hline TR0523 & White & TR0329 & White & TR0593 & White \\
\hline TR0092 & White & TR0864 & White & TR0589 & White \\
\hline TR1198 & Yellow & TR0302 & White & TR0345 & White \\
\hline TR1028 & Yellow & TR1005 & White & TR0135 & White \\
\hline TR0949 & Yellow & TR1162 & White & TR1436 & White \\
\hline TR0300 & Yellow & TR0159 & White & TR1326 & Yellow \\
\hline TR0356 & White & TR0006 & White & TR0454 & White \\
\hline TR1769 & White & TR0255 & White & TR1736 & White \\
\hline TR0024 & White & TR0435 & White & TR0724 & White \\
\hline TR0275 & White & TR0428 & White & TR0310 & White \\
\hline TR0694 & Yellow & TR1791 & White & TR0417 & White \\
\hline TR0912 & White & TR0288 & White & TR0120 & White \\
\hline TR0105 & White & TR1716 & Yellow & TR0164 & White \\
\hline TR0171 & White & TR0432 & White & TR0263 & White \\
\hline TR0488 & White & TR0297 & Yellow & TR0590 & White \\
\hline SLICASS4 & White & TR1167 & White & TR0382 & Yellow \\
\hline TR0746 & White & TR1175 & White & TR0453 & White \\
\hline TR0740 & White & TR0821 & White & TR1154 & White \\
\hline TR0204 & White & TR0657 & White & TR1097 & White \\
\hline TR1518 & Yellow & TR1035 & Yellow & TR0545 & White \\
\hline TR0064 & White & TR1618 & Yellow & TR1041 & Yellow \\
\hline TR0455 & White & TR0613 & White & TR0745 & White \\
\hline TR0779 & White & TR0358 & White & TR0017 & White \\
\hline TR0820 & White & TR1796 & Yellow & TR0591 & White \\
\hline TR0915 & White & TR1288 & White & TR1159 & White \\
\hline TR1824 & White & TR0667 & White & TR1776 & White \\
\hline TR0812 & White & TR0256 & White & $\mathrm{COCO}$ & White \\
\hline
\end{tabular}

dried with forced drought oven. Samples were reweighed again to obtain a constant weight after $72 \mathrm{~h}$ at $65-70{ }^{\circ} \mathrm{C}$ (Fukuda et al. 2010).

\section{Molecular characterization}

DNA was extracted at the International Institute of Tropical Agricultural Bioscience Laboratory IITA, Ibadan, Nigeria using the method proposed by Dellaporta et al. (1983) with a slight modification described by Rabbi et al. (2014). Freshly harvested apical leaves of about $200 \mathrm{mg}$ of each accession were used. Grinding of the leaf samples was done in a $1.2 \mathrm{ml}$ extraction tube using $400 \mu \mathrm{l}$ extraction buffer and then placed in a $65{ }^{\circ} \mathrm{C}$ water-bath for $25 \mathrm{~min}$ with gentle shaking. The tube was removed from the water bath and allowed to cool for 5-10 min. Proteins and polysaccharides were precipitated by adding $200 \mu \mathrm{l}$ of icecold $5 \mathrm{M}$ potassium acetate and then mixed by gentle inversions (this was placed on ice for $20 \mathrm{~min}$ ). About $350 \mu \mathrm{l}$ chloroform:isomyl alcohol was added (24:1) to the content and mixed gently with continuous rocking and centrifuged at $4000 \mathrm{~g}$ for $10 \mathrm{~min}$. This was followed by the addition of RNase. The crude pellets were precipitated by transferring the upper layer to a new tube. One volume $(400 \mu \mathrm{l})$ of ice-cold isopropanol was added and mixed gently for about 2-3 min and then chilled in $-20{ }^{\circ} \mathrm{C}$ 
Table 2 Qualitative and quantitative traits used to characterize 102 cassava genotypes

\begin{tabular}{|c|c|c|c|c|}
\hline $\mathrm{SN}$ & Trait descriptor & $\begin{array}{l}\text { Trait } \\
\text { acronym }\end{array}$ & Score code & $\begin{array}{l}\text { Sampling } \\
\text { time }\end{array}$ \\
\hline \multicolumn{5}{|c|}{ Qualitative traits } \\
\hline 1 & Color of leaf vein & CLV & $\begin{array}{l}3=\text { green; } 5=\text { reddish green in }<\text { half of lobe; } 7=\text { reddish green in }>\text { half of lobe; } 9=\text { all } \\
\text { red }\end{array}$ & 6 MAP \\
\hline 2 & Root taste & RT & $1=$ sweet $; 2=$ intermediate $; 3=$ bitter & 12 MAP \\
\hline 3 & $\begin{array}{l}\text { Cassava mosaic } \\
\text { disease }\end{array}$ & CMD & $1=$ no visible symptom of disease $; 2=$ mild $; 3=$ low $;=$ intermediate $; 5=$ high & 6 MAP \\
\hline 4 & Color of root pulp & CRP & $1=$ white $; 2=$ cream; $3=$ yellow; $4=$ orange $;=$ pink & 12 MAP \\
\hline 5 & Lobe margins & LM & $3=$ smooth $; 7=$ winding & 6 MAP \\
\hline 6 & Ease of peeling & $\mathrm{EP}$ & $1=$ easy; 2 = difficult & 12 MAP \\
\hline 7 & Leaf color & $\mathrm{LC}$ & $3=$ light green; $5=$ dark green; $7=$ purple green; $9=$ purple & 6 MAP \\
\hline 8 & $\begin{array}{l}\text { Color of apical } \\
\text { leaves }\end{array}$ & CAL & $3=$ light green; $5=$ dark green; $7=$ purplish green; $9=$ purple & 3 MAP \\
\hline 9 & Root shape & RS & $1=$ conical $; 2=$ conical-cylindrical $; 3=$ cylindrical $; 4=$ irregular & 12 MAP \\
\hline 10 & $\begin{array}{l}\text { Shape of central } \\
\text { leaflet }\end{array}$ & SCL & $\begin{array}{l}1=\text { ovoid } ; 2=\text { elliptical-lanceolate; } 3=\text { obovate-lanceolate; } 4=\text { oblong-lanceolate; } \\
5=\text { lanceolate; } 6=\text { straight; } 7=\text { pandurate; linear-piramidal; linear-pandurate; linear- } \\
\text { hostatilobalate }\end{array}$ & 6 MAP \\
\hline 11 & $\begin{array}{l}\text { External color of } \\
\text { storage root }\end{array}$ & ECSR & $1=$ white or cream; $2=$ yellow; $3=$ light brown; $4=$ dark brown & 12 MAP \\
\hline \multicolumn{5}{|c|}{ Quantitative traits } \\
\hline 12 & $\begin{array}{l}\text { Number of storage } \\
\text { roots/plant }\end{array}$ & NSR & Count & 12 MAP \\
\hline 13 & Harvest index & $\mathrm{HI}$ & Derived estimate & 12 MAP \\
\hline 14 & Root yield per plant & RYPP & Derived estimate & 12 MAP \\
\hline 15 & $\begin{array}{l}\text { Root dry matter } \\
\text { content }(\%)\end{array}$ & RDMC & Direct measurement & 12 MAP \\
\hline 16 & Starch content $(\%)$ & STC & Direct measurement & 12 MAP \\
\hline 17 & Number of leaf lobe & NLL & Count & 6 MAP \\
\hline 18 & Petiole length & PL & Direct measurement using meter rule & 6 MAP \\
\hline 19 & Plant height & $\mathrm{PH}$ & Direct measurement using meter rule & 12 MAP \\
\hline 20 & Length of leaf lobe & LLL & Direct measurement using meter rule & 6 MAP \\
\hline 21 & Width of leaf lobe & WLL & Direct measurement using caliper & 6 MAP \\
\hline 22 & $\begin{array}{l}\text { Height at first } \\
\text { branching }\end{array}$ & HFB & Direct measurement using meter rule & 12 MAP \\
\hline
\end{tabular}

freezer for $10 \mathrm{~min}$ to enhance DNA precipitation. It was then centrifuged at $4500 \mathrm{~g}$ for $20 \mathrm{~min}$ and the supernatant was carefully discarded.

\section{SNP genotyping}

For SNP genotyping, about $50 \mu \mathrm{l}$ concentrated DNA sample of each sample was sent to Cornell University for genotyping-by-sequencing analysis. The GBS was determined as described by Elshire et al. (2011) and sequenced at the Institute of Genomic Diversity at Cornell University using the Illumina HiSeq 2500. The raw HapMap file from Cornell University was first converted to a Variant call format (VCF) for the analysis using perl programming language and TASSEL 5.0 (Bradbury et al. 2007; Elshire et al. 2011). The VCF file was filtered for missing value and polymorphic SNPs with quality parameter and a call rate greater than $80 \%$, depth $>95 \%$, and minor allele frequency of 0.01 . The SNPs with MAF values less than 0.01 and loci with more than $40 \%$ missing SNP marker data were considered non-informative and were removed. Of the 8600 SNPs subjected to filtering, 5600 informative SNP markers were retained for genetic diversity study.

\section{Data analysis}

\section{Qualitative and quantitative phenotypic data analysis}

The genetic variation among the studied genotypes for agro-morphological traits was explored using multivariate 
analysis technique. Multivariate analysis of the $102 \times 11$ qualitative data matrix and $102 \times 11$ quantitative data matrix comprising of principal component analysis (PCA) were performed separately in SAS 9.4 software version. In the PCA, Eigen-values and load coefficient values were generated from the data set. The relevance of trait contribution to the variation accounted by each principal component was based on the absulute eigenvector arbitrary cutoff value of 0.30 (Richman 1988). The PCA and correlation matrices were used to determine the relationships among the traits. The organization and structure of the morphological variability were visualized using the Ascending Hierarchical Clustering (AHC) to plot a dendrogram.

\section{Molecular data analysis}

The genetic analysis package Power Marker version 3.0 (Liu and Muse 2005) was used to generate pairwise distance-based hierarchical clustering.

\section{Results}

\section{Frequency distribution of accessions according to qualitative traits}

Frequency distributions of the qualitative traits are presented in Figs. 1 and 2. Genetic variability was observed among the 102 cassava accessions for all of the variables evaluated. The results showed that $53.9 \%$ of the accessions exhibited light-green leaves, $42.2 \%$ had dark-green leaves and $3.9 \%$ had purple-green leaves (Fig. 1a). About $67 \%$ of the accessions had green leaf vein, $27 \%$ had reddish-green in more than half of lobe and $6 \%$ had reddish-green in less than half of the lobe (Fig. 1b). Lobe margin of 52\% of the accessions was smooth, while $48 \%$ had winding lobe margin (Fig. 1c). The shapes of the central leaflet of the accessions were $2.0 \%$ linear pandurate, $27.5 \%$ linear pyramidal, $29.4 \%$ pandurate, $24.5 \%$ oblong-lanceolate, $6.9 \%$ straight or linear, $2.9 \%$ lanceolate, $3.9 \%$ obovatelanceolate and $2.9 \%$ ovoid (Fig. 1d). The accessions exhibited $74.0 \%$ no symptom, $14.0 \%$ mild symptom, $10.0 \%$ moderate symptom, $2.0 \%$ severe symptom and $0 \%$ (a)

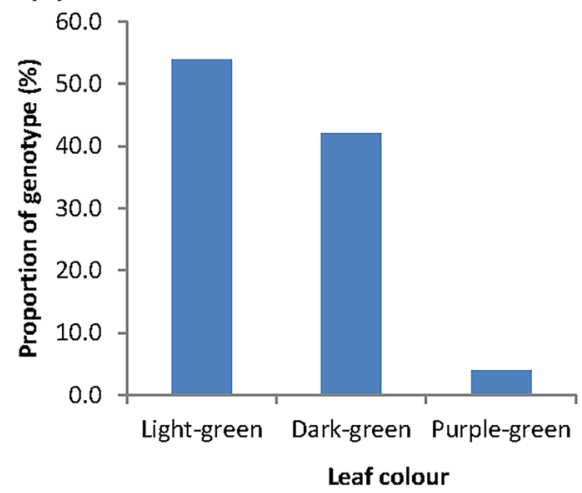

(d)

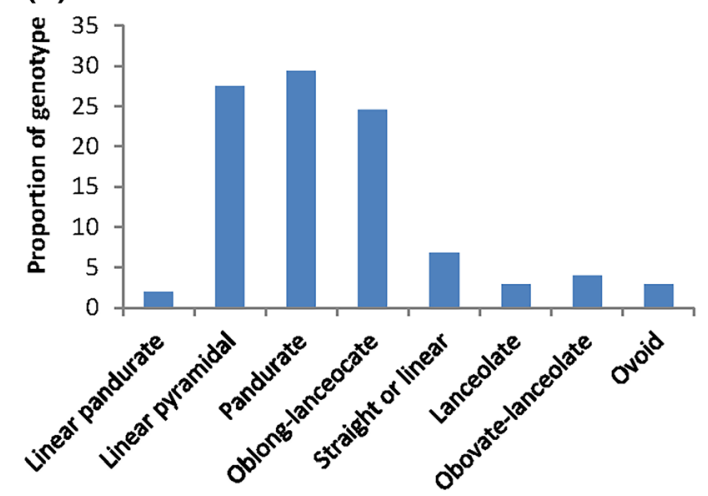

Shape of central leaflet (b)

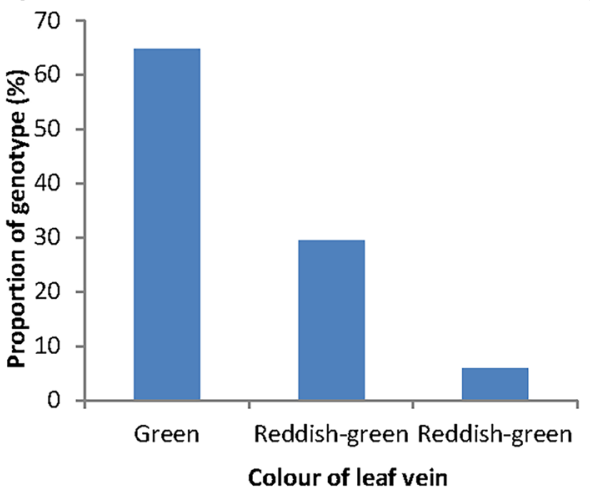

(e) (c)

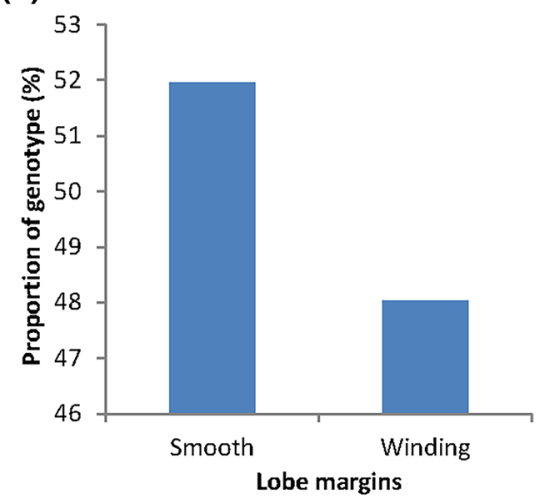

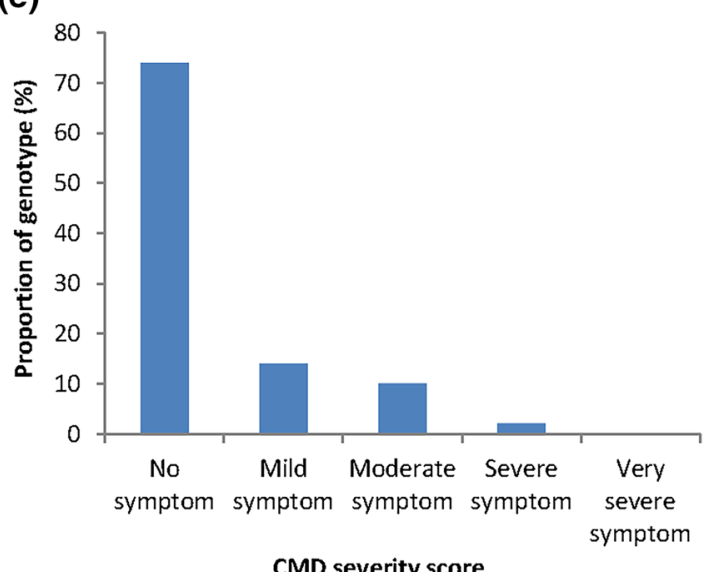

CMD severity score

Fig. 1 Percent distribution of a leaf color; $\mathbf{b}$ color of leaf vein; $\mathbf{c}$ lobe margins; $\mathbf{d}$ shape of central leaflet; and e cassava mosaic disease among 102 genotypes of cassava 
(a)

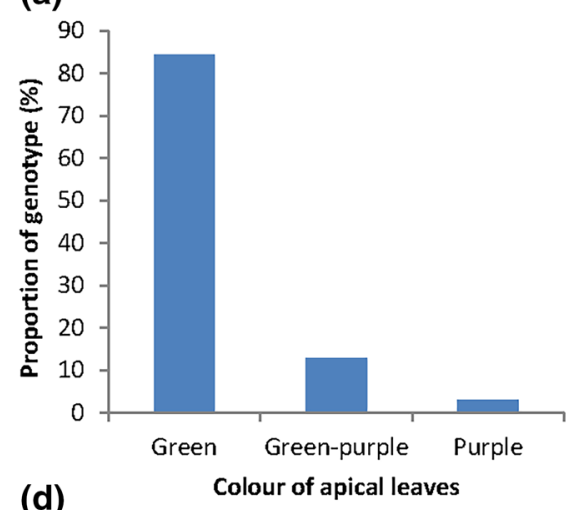

(d)

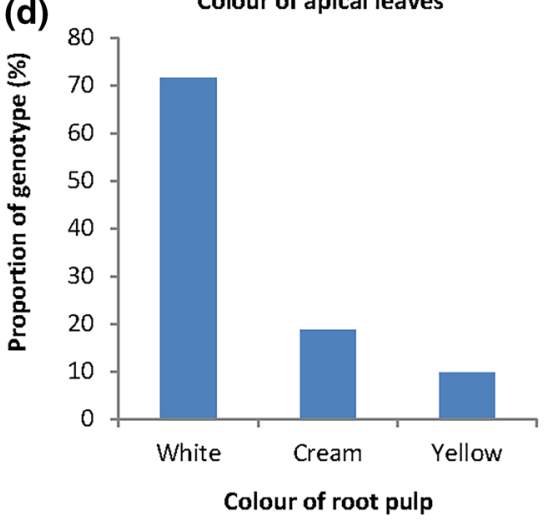

(b)

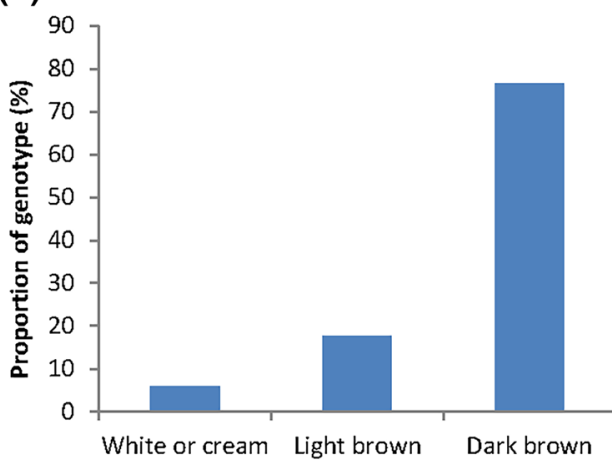

(e)

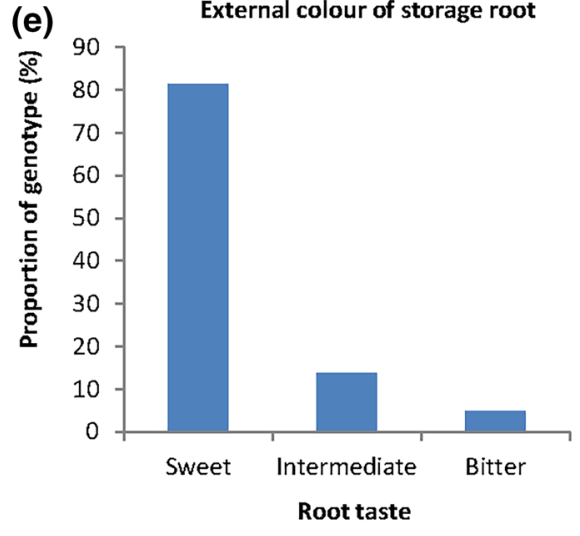

(c)

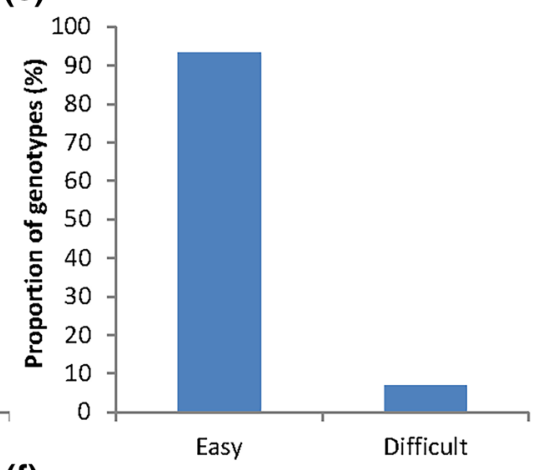

(f)

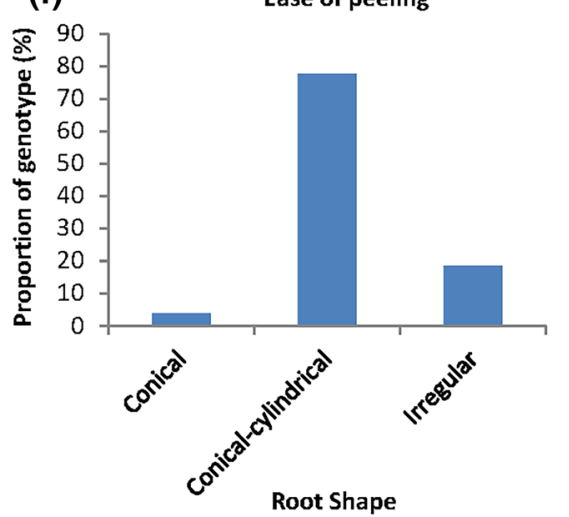

Fig. 2 Percent distribution of a color of apical leaves; b external color of storage root; $\mathbf{c}$ ease of peeling; $\mathbf{d}$ color of root pulp; e root taste; and f root shape among 102 genotypes of cassava

very severe symptom of cassava mosaic disease severity (Fig. 1e).

In terms of color of apical leaves, $84.3 \%, 12.7 \%$ and $2.9 \%$ genotypes had light green, green purple and purple apical leaves, respectively (Fig. 2a). For external color of storage roots, $5.9 \%$ of the accessions had white or cream, $17.6 \%$ light brown and $76.5 \%$ dark brown storage roots (Fig. 2b). Approximately $90.1 \%$ of accessions were easy to peel while $9.8 \%$ were difficult to peel (Fig. 2c). About $70.6 \%$ of the accessions had white root pulp, while $19.6 \%$ had cream root pulp and $9.8 \%$ had yellow root pulp (Fig. 2d). About $79.4 \%$ of the accessions had sweet root taste, $14.7 \%$ were classified as intermediate and $5.9 \%$ had bitter root taste (Fig. 2e). The accessions comprised of three root shapes including conical (3.9\%), conical-cylindrical (77.5\%) and irregular (18.6\%) (Fig. 2f).

\section{Principal component analysis of qualitative characters}

The eigenvalues and percentage variations of the principal component analysis are presented in Table 3. Seven principal components that accounted for $79.03 \%$ of the total variation among the genotypes were identified. The first PC axis with eigenvalue of 1.73 accounted for $15.76 \%$ of the total variation where the second, third and the fourth PC axes with eigenvalues of $1.70,1.35$ and 1.14 accounted for $15.43 \%, 12.24 \%$ and $10.38 \%$ of the total variation, respectively. The fifth, sixth and seventh PC axes with eigenvalues of $0.99,0.97$ and 0.83 accounted for $8.99 \%$, $8.84 \%$ and $7.43 \%$ of the total variation, respectively.

The first principal component with reference to its high factor loadings was positively associated with traits such as root taste, color of root pulp, ease of peeling, and root shape. The second PC was associated with leaf and storage root characteristics (root taste, leaf color, and color of apical leaves); the third PC was associated with external color of storage root, ease of peeling, color of leaf vein and shape of central leaf lobe, while the fourth PC was associated with traits related to storage root characteristics (color of root pulp, external color of storage root, and root shape) color of leaf vein and cassava mosaic disease. The fifth PC was associated with characteristics such as root taste, cassava mosaic disease, root shape, lobe margin and color of apical leaves, the sixth PC was also associated with external color of storage root, cassava mosaic disease and lobe margin and the seventh PC was also associated with storage (root color of root pulp and root shape) and cassava mosaic disease. 


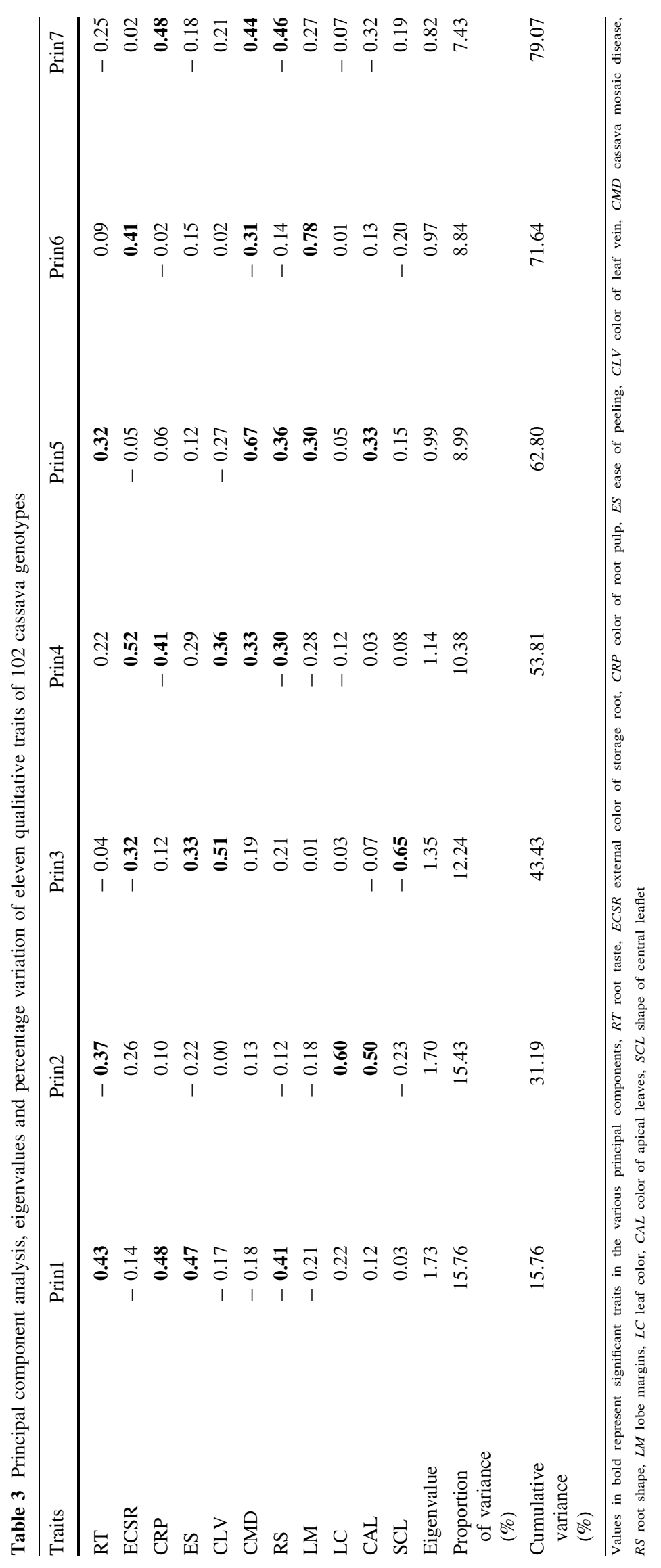




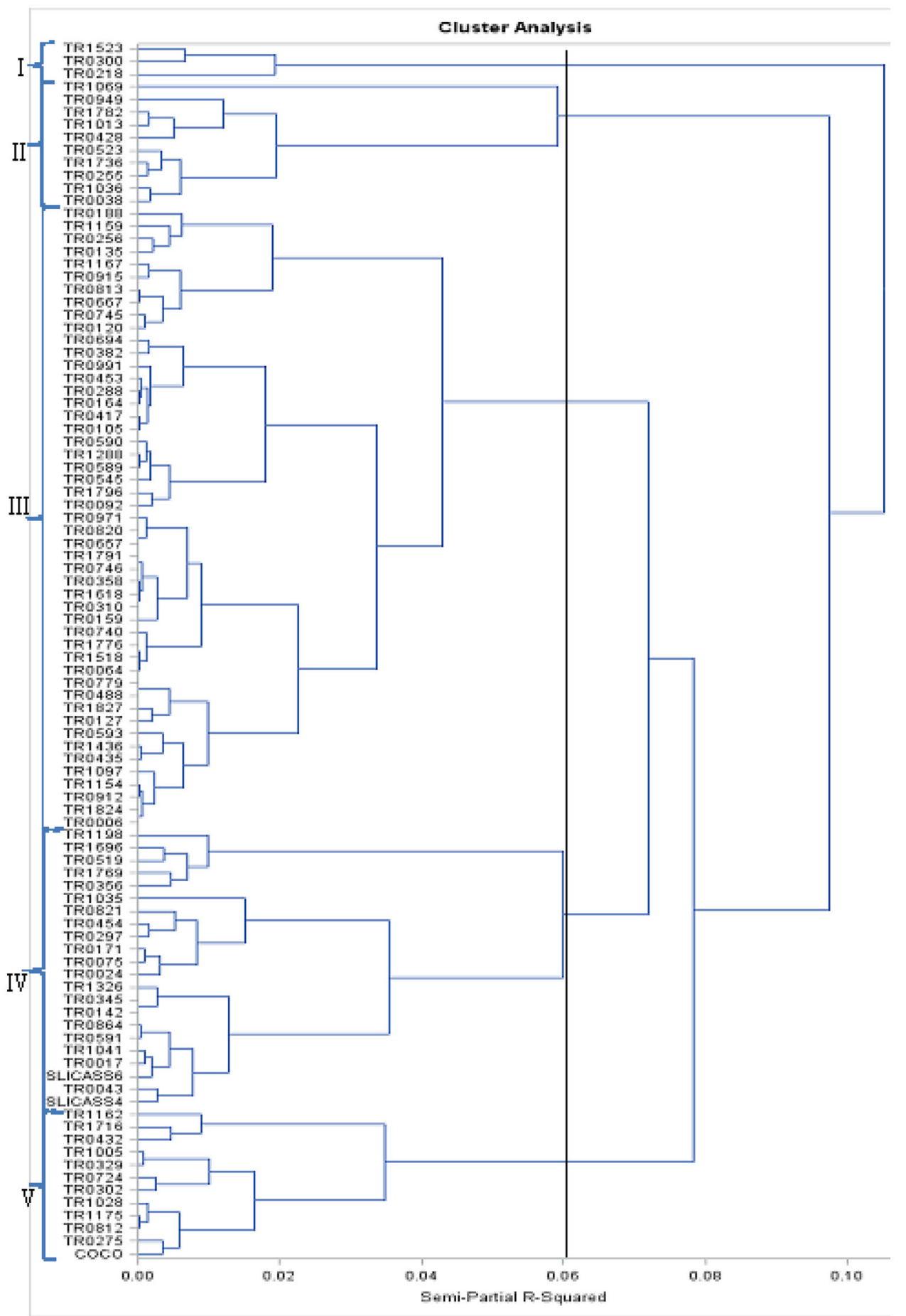

Fig. 3 Dendrogram showing relationships among 102 genotypes of cassava classified by Ward method using eleven 11 qualitative agromorphological traits

\section{Genetic relationship among 102 cassava genotypes using 11 qualitative traits}

The hierarchical classification of qualitative traits grouped genotypes into five classes almost with the same characteristics as a function of the variables (Fig. 3). The genetic similarity for the 11 qualitative traits ranged from zero to one with a mean similarity of 0.10 . The cassava genotypes were grouped into five distinct clusters at 0.06 similarities. Groups III, IV and V have a high number of genotypes with 55, 22 and 12, respectively. Ten and 3 individuals were in clusters II and I, respectively (Fig. 3). 
Table 4 Probability values, means and coefficient of variation of quantitative traits of 102 cassava genotypes

\begin{tabular}{llllllllllll}
\hline Source & HI & AYPP & PL & LLL & WLL & RDMC & NSR & STC & PH & NLL & HFB \\
\hline Genotype & $<.0001$ & $<.0001$ & $<.0001$ & $<.0001$ & 0.9709 & 0.214 & $<.0001$ & 0.3192 & 0.7652 & $<.0001$ & 0.0098 \\
Mean & 0.45 & 1.56 & 13.5 & 10.6 & 4.4 & 30.9 & 7.5 & 23.9 & 149.1 & 5.8 & 58.9 \\
CV & 19.1 & 32.7 & 20.9 & 11.6 & 100.4 & 8.8 & 23.1 & 11.8 & 17.55 & 17.3 & 55.1 \\
\hline
\end{tabular}

Significant at alpha $=0.05 . H I$ harvest index, AYPP average yield per plant $(\mathrm{kg}), P L$ petiole length $(\mathrm{cm}), L L L$ length of leaf lobe $(\mathrm{cm}), W L L$ width of leaf lobe $(\mathrm{cm}), R D M C$ root dry matter content (\%), NSR number of storage roots (count), STC starch content $(\%), P H$ plant height $(\mathrm{cm}), H F B$ height at first branching (cm), NLL number of number of leaf lobe

Table 5 Correlation coefficients among 11 quantitative traits of 102 cassava genotypes

\begin{tabular}{|c|c|c|c|c|c|c|c|c|c|c|c|}
\hline & $\mathrm{HI}$ & RYPP & PL & LLL & WLL & RDMC & NSR & STC & $\mathrm{PH}$ & HFB & NLL \\
\hline $\mathrm{HI}$ & 1.00 & & & & & & & & & & \\
\hline RYPP & $0.76 * * *$ & 1.00 & & & & & & & & & \\
\hline PL & 0.01 & 0.11 & 1.00 & & & & & & & & \\
\hline LLL & 0.14 & 0.23 & 0.38* & 1.00 & & & & & & & \\
\hline WLL & -0.19 & -0.01 & $0.23 *$ & $0.36 *$ & 1.00 & & & & & & \\
\hline RDMC & 0.08 & 0.00 & -0.04 & 0.01 & -0.16 & 1.00 & & & & & \\
\hline NSR & 0.33* & $0.58 * *$ & 0.14 & 0.19 & 0.01 & 0.03 & 1.00 & & & & \\
\hline STC & 0.08 & 0.00 & -0.05 & 0.00 & -0.16 & $0.99 * * *$ & 0.05 & 1.00 & & & \\
\hline $\mathrm{PH}$ & 0.16 & 0.03 & 0.06 & -0.18 & -0.17 & 0.00 & -0.03 & -0.03 & 1.00 & & \\
\hline HFB & $0.26 *$ & $0.24 *$ & -0.04 & $-0.27 *$ & $-0.21 *$ & 0.06 & 0.08 & 0.05 & $0.45 * *$ & 1.00 & \\
\hline NLL & 0.05 & -0.03 & $0.31 *$ & $0.43 * *$ & 0.19 & $0.30 *$ & 0.11 & $0.28 *$ & 0.07 & -0.03 & 1.00 \\
\hline
\end{tabular}

Significant at alpha $=0.05 . H I$ harvest index, RYPP root yield per plant $(\mathrm{kg}), P L$ petiole length $(\mathrm{cm}), L L L$ length of leaf lobe (cm), WLL width of leaf lobe (cm), RDMC root dry matter content (\%), NSR number of storage roots (count), STC starch content (\%), PH plant height (cm), HFB height at first branching (cm), NLL number of leaf lobe

\section{Mean values and correlation coefficients for the eleven quantitative traits}

The mean values for harvest index, root yield per plant, root dry matter content, number of storage roots and starch content were $0.5,1.6 \mathrm{~kg}, 30.9 \%, 7.5$ and $23.9 \%$, respectively (Table 4). Significant and positive correlations were observed between root yield per plant and harvest index $\left(\mathrm{r}=0.76^{* * *}\right)$, number of storage roots per plant and harvest index $\left(\mathrm{r}=0.33^{*}\right)$, height at first branching and harvest index $\left(0.26^{*}\right)$, number of storage roots per plant and root yield per plant $\left(\mathrm{r}=0.58^{*}\right)$, height at first branching and root yield per plant $\left(\mathrm{r}=0.24^{*}\right)$, length of leaf lobe and petiole length $\left(\mathrm{r}=0.38^{*}\right)$, width of leaf lobe and petiole length $\left(r=0.23^{*}\right)$, number of leaf lobe and petiole length $\left(\mathrm{r}=0.31^{*}\right)$, width of leaf lobe and length of leaf lobe $\left(\mathrm{r}=0.36^{*}\right)$, number of leaf lobe and length of leaf lobe $\left(\mathrm{r}=0.43^{*}\right)$, starch content and root dry matter content ( $\mathrm{r}=0.99 * * *)$, number of leaf lobe and root dry matter content $\left(r=0.30^{*}\right)$, number of leaf lobe and starch content $\left(\mathrm{r}=0.28^{*}\right)$, and height at first branching and plant height $\left(\mathrm{r}=0.45^{* *}\right)$ (Table 5). Conversely, significant and negative associations were noted between height at first branching and length of leaf lobe $(-0.27 *)$, and between height at first branching and width of leaf lobe $\left(-0.21^{*}\right)$.

\section{Representation of variables of quantitative traits}

The result revealed that the four main components accounted for $72.30 \%$ of the total variation among the genotypes. The first factorial plane contains $22.18 \%$ of the variance. The variables that significantly correlated with axis 1 are: harvest index (47\%), root yield per plant (49\%), root dry matter content $(30 \%)$, number of storage roots (40\%), and starch percentage $(30 \%)$. The variables that were significantly correlated with axis 2 are: petiole length $(37 \%)$, length of leaf lobe $(51 \%)$, width of leaf lobe $(47 \%)$ and height at first branching $(-37 \%)$. The variables significantly related to axis 3 are: root yield per plant $(-35 \%)$, root dry matter content $(55 \%)$, starch content $(55 \%)$ and number of leaf lobes $(30 \%)$. The variables significantly correlated with axis 4 are: petiole length (40\%), plant height (64\%), height at first branching (40\%) and number of leaf lobe $(36 \%)$ (Table 6).

\section{Genetic relationship among 102 cassava genotypes using 11 quantitative traits}

Hierarchical classification of quantitative traits grouped genotypes into four classes almost with the same characteristics as a function of the variables (Fig. 4). The genetic 
Table 6 Principal component analysis, eigenvalues, percentage variation and cumulative variance of eleven quantitative traits of 102 cassava genotypes

\begin{tabular}{|c|c|c|c|c|}
\hline Traits & Prin1 & Prin 2 & Prin3 & Prin4 \\
\hline HI & 0.47 & -0.11 & -0.28 & -0.13 \\
\hline RYPP & 0.49 & 0.02 & $-\mathbf{0 . 3 5}$ & -0.23 \\
\hline PL & 0.17 & 0.37 & 0.00 & 0.40 \\
\hline LLL & 0.24 & 0.51 & 0.06 & 0.02 \\
\hline WLL & -0.05 & 0.47 & 0.03 & 0.10 \\
\hline RDMC & 0.30 & -0.22 & 0.55 & -0.07 \\
\hline NSR & 0.40 & 0.10 & -0.20 & -0.21 \\
\hline STC & 0.30 & -0.21 & 0.55 & -0.10 \\
\hline $\mathrm{PH}$ & 0.10 & -0.27 & -0.14 & 0.64 \\
\hline HFB & 0.19 & $-\mathbf{0 . 3 7}$ & -0.20 & 0.40 \\
\hline NLL & 0.26 & 0.26 & 0.30 & 0.36 \\
\hline Eigenvalue & 2.44 & 2.14 & 2.07 & 1.31 \\
\hline Proportion of variance $(\%)$ & 22.18 & 19.42 & 18.83 & 11.87 \\
\hline Cumulative variance (\%) & 22.18 & 41.60 & 60.43 & 72.30 \\
\hline
\end{tabular}

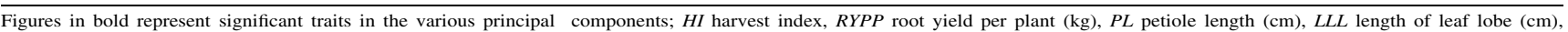
$W L L$ width of leaf lobe $(\mathrm{cm}), R D M C$ root dry matter content $(\%), N S R$ number of storage roots (count), STC starch (\%), PH plant height (cm), HFB height at first branching $(\mathrm{cm}), N L L$ number of leaf lobe (count)

similarity for the eleven quantitative traits ranged from zero to one with a mean similarity of 0.10 . Cluster I contains 19 genotypes, cluster II 12 genotypes, cluster III 46 genotypes and cluster IV 25 genotypes.

\section{Clustering analysis using SNPs marker}

The dendrogram showing clustering analysis of 96 cassava genotypes based on 5600 SNP markers is presented in Fig. 5. At similarity of 0.41 , the result revealed three main clusters. At similarity of 0.37 , the accessions were further divided into 7 sub-clusters. Cluster I consists of two subclusters: sub-clusters A and B. Sub-cluster A had two genotypes (TR0971 and TR0912) and sub cluster B contained 18 accessions. Cluster II consists of two sub-clusters: sub-clusters $\mathrm{C}$ and D. Sub-cluster $\mathrm{C}$ comprises of 6 accessions; while sub-cluster D contains 22 accessions. Cluster III consists of four sub-clusters: sub-clusters E, F, $\mathrm{G}$ and $\mathrm{H}$ comprising 5, 33, 3 and 6 accessions, respectively.

\section{Discussion}

The analysis of qualitative morphological traits (root taste, external color of storage root, color of root pulp, ease of peeling, color of leaf vein, cassava mosaic disease, lobe margins, leaf color, color of apical leaves and shape of central leaflet) showed a significant variation among the studied genotypes. Color was apparently the most representative and the most distinctive trait possibly due to the fact that most of the genotypes exhibited white root pulp, and dark brown external storage root. The above-ground leaf attributes of the studied genotypes were light green apical leaves, light green leaf, green leaf vein, smooth lobe margin and pendurate central leaflets. The leaf attributes play key role in cultivar identification and are more important for selection of cassava for the leafy vegetable markets in Sierra Leone where cassava leaves are consumed. These findings concur with Agre et al. (2016) who reported that farmers use the color of the leaves and stems to identify their cassava cultivars.

The principal component analysis is a powerful data reduction technique utilized to reduce large number of correlated variables to a small number that is independent and very useful. The PCA unraveled traits that contributed most to the variation present in the cassava germplasm. The qualitative traits that contributed positively highest to the first PCA include root taste, color of root pulp and ease of peeling. Findings of this study indicate the usefulness of these traits for genotype identification and genetic diversity studies in cassava. These are among key traits often considered relevant for selection of varieties for the genetic improvement of the crop.

The clustering based on similarity index of the qualitative traits in this study grouped the 102 cassava accessions into five clusters. Cluster I contained the accessions characterized by green apical leaves, cluster II grouped accessions having green apical leaves, smooth lobe of leaf margin and resistance to cassava mosaic disease. Cluster III was grouped based on ease of peeling, sweet root taste and 


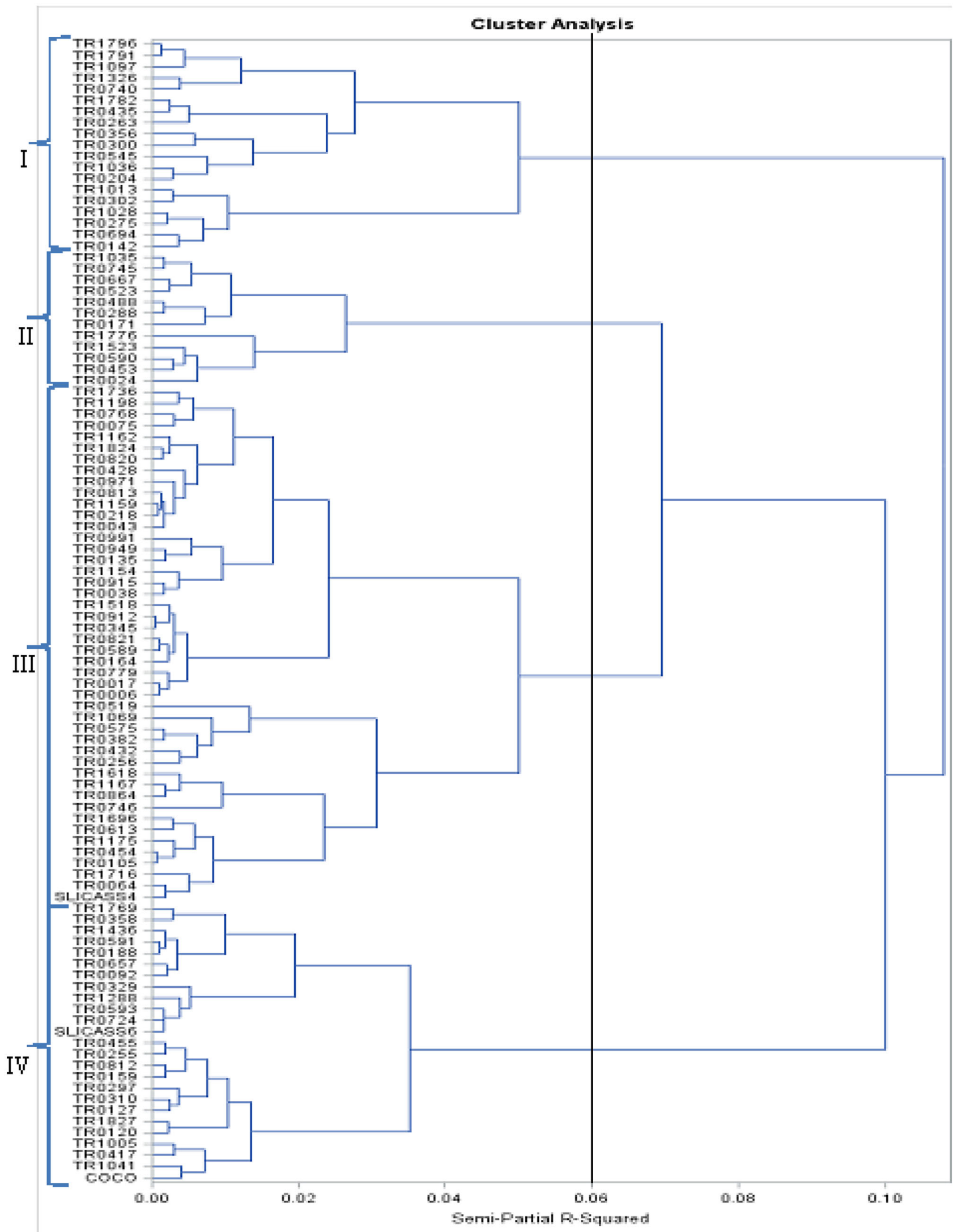

Fig. 4 Dendrogram showing relationships among 102 genotypes of cassava classified by Ward method using eleven 11 quantitative agromorphological traits 


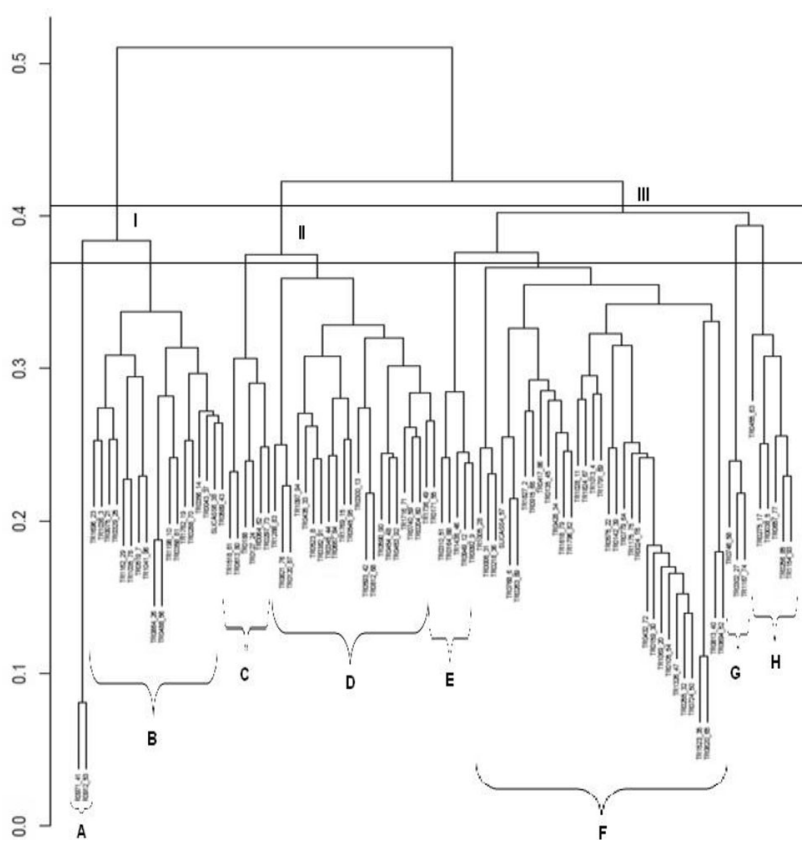

Fig. 5 Dendrogram generated by UPGMA method of 96 cassava accessions based on SNP markers

conical cylindrical root shape. Cluster IV had light green leaves and green apical leaves. Cluster $\mathrm{V}$ contained accessions with dark brown external storage roots, light green leaves and ease of peeling. In a similar study, Raghu et al. (2007) identified six distinct groups using 58 cassava accessions. In this study, the first two principal components explained $31.18 \%$ of the total cumulative variance for the qualitative traits. This result is similar with those of Afonso et al. (2014) who found $32.56 \%$ of the genetic variance in the first factorial plane. It can also be explained by the fact that the variance distribution is associated with the nature and number of characters used in the analysis and focuses on the first principal components.

The analysis of the 11 quantitative traits revealed significant differences, seven of which had high coefficients of variation. The high coefficients of variation observed for the examined characters indicated the presence of high heterogeneity within the population and therefore can be exploited for breeding. Similar results for cassava were obtained in Benin by Agre et al. (2015) where some averages were identical in cassava diversity study. In this study, starch was positively and highly correlated with dry matter content indicating that starch content and dry matter content are closely related. Similar studies conducted at CIAT and IITA have established that dry matter content and starch content are closely correlated $(r=0.81)$ (IITA 1974; CIAT 1975).

The first four principal components analysis explained $72.30 \%$ of the overall variability in the quantitative analysis. Principal components I, II and III obtained from quantitative variables present yield and yield attribute traits such as harvest index, average yield per plant, number of storage root, root dry matter content and starch content that may be integrated into a cassava breeding program. The quantitative traits with highest positive contribution to distinguishing genotypes in the first PCA included harvest index, average yield per plant, number of storage roots, root dry matter content and starch content. These are among key traits often considered relevant for selection of varieties and for the genetic improvement of the crop. The cluster analysis of the 11 quantitative agro-morphological traits also grouped the accessions into four clusters. Cluster I accessions were characterized by high starch content, root dry matter content and harvest index. Cluster II accessions were characterized by high root dry matter content and fresh storage root yield. Cluster III accessions exhibited high starch content; whilst cluster IV accessions contained high root dry matter content. The results generally indicate the relevance of the above yield and yield attribute traits in characterizing the genotypes. It also depicts the usefulness of the agro-morphological descriptor by Fukuda et al. (2010) in identifying variability and reducing dimensionality in the traits set. In this study, the 11 qualitative and 11 quantitative trait sets sufficiently discriminated the 102 genotypes into distinct cluster groups. All accessions differ from each other in one or more traits with no detection of duplicates, which suggest their usefulness in genotypic differentiation and identification.

Findings of the molecular study revealed that $96 \%$ of the 5600 SNP markers were polymorphic. The highest polymorphic information content (PIC) value observed was 0.17 . The variation observed reflect the genetic constitution of the accessions. In a previous study on cassava genetic diversity using SNPs, Kawuki et al. (2009) reported PIC values of 0.228 in 74 cassava accessions. Moreover, in maize, Yang et al. (2011) reported a higher PIC value of 0.34 using 884 SNP markers. The variance in PIC values among these studies could be attributed to the number of genotypes and type of SNP markers used. Both the morphological and SNP markers established the uniqueness and variability within the cassava germplasm utilized in this study. The unique diversity in the cassava germplasm suggests that the germplasm might possess genes, in high frequencies, for adaptation in the studied area, whereas the high genetic diversity is indicative of a high amount of additive genetic variance, needed for genetic progress in plant breeding. The high genetic variability also represents a heterotic pool that provides an opportunity for the systematic exploitation of hybrid vigor in cassava. Although high diversity has been noted for African cassava germplasm (Lyimo et al. 2012), however, such diversity is still lower than those observed in Southern America cassavas (Hurtado et al. 2008; da Silva et al. 2015). Unlike the later 
where farmers use seedling and vegetative propagation techniques (Siqueira et al. 2009; Mezette et al. 2013), farmers in Sierra Leone only propagate the crop using stem cuttings. This study established the true-to-type genetic identity and useful variability within cassava germplasm of Sierra Leone needed for the genetic improvement and conservation of the crop.

\section{Conclusion}

This study successfully determined the extent of genetic diversity within cassava breeding population of Sierra Leone using morphological and SNP markers. It also provides a data base for cassava breeders to make informed decision for parental selection in a cassava breeding program based upon genetic diversity. The useful genetic variability for storage root number, starch content, root dry matter content and storage root yield that were identified could be exploited for the genetic improvement of the crop and its conservation. The color attribute of various qualitative traits studied contributed most to the differentiation of genotypes. The agro-morphological and SNP marker techniques were complementary in distinguishing the cassava genotypes. Both approaches should therefore be used for genetic diversity studies of cassava.

Acknowledgements The authors are grateful to the cassava breeding team at the International Institute of Tropical Agricultural Nigeria (IITA) for their technical support during the course of this study.

Author contributions All authors contributed to the study conception and design. Material preparation, data collection and analysis were performed by KYK, JBAW, PK, IR, EP, LO, PEN and PI. The supervision was done by BI, DD, EYD, ETB and JBAW. The first draft of the manuscript was written by KYK and PEN, and all authors commented on previous versions of the manuscript. All authors read and approved the final manuscript.

Funding This research was funded by the International Development Research Centre (IDRC) under the IDRC/CORAF-WECARD/IITA sub-grant agreement for developing capacity for Agricultural Research in Sub-Saharan Africa (PJ-2126) to pursue PhD in Plant Breeding at the West African Centre for Crop Improvement (WACCI), University of Ghana; and the West Africa Agricultural Productivity Program Sierra Leone (WAAPP 1C SL) Grant Number: IDA Grant H654-SL and Japan PHRD TF099510-SL.

\section{Compliance with ethical standards}

Conflict of interest The authors declare that they have no conflict of interest.

Open Access This article is licensed under a Creative Commons Attribution 4.0 International License, which permits use, sharing, adaptation, distribution and reproduction in any medium or format, as long as you give appropriate credit to the original author(s) and the source, provide a link to the Creative Commons licence, and indicate if changes were made.The images or other third party material in this article are included in the article's Creative Commons licence, unless indicated otherwise in a credit line to the material. If material is not included in the article's Creative Commons licence and your intended use is not permitted by statutory regulation or exceeds the permitted use, you will need to obtain permission directly from the copyright holder.To view a copy of this licence, visit http://creativecommons.org/licenses/by/4.0/.

\section{References}

Afonso SDJ, Ledo CAdaS, Moreira RFC, Silva SdeOe, Leal VDdeJ, Conceição ALdaS (2014) Selection of descriptors in a morphological characteristic considered in cassava accessions by means of multivariate techniques. IOSR-JAVS 7: 13-20

Agre AP, Dansi A, Rabbi IY, Battachargee R, Dansi M, Melaku G, Augusto B, Sanni A, Akouegninou A, Akpagana K (2015) Agro morphological characterization of elite cassava (Manihot esculenta Crantz) cultivars collected in Benin. Int J Curr Res Biosci Plant Biol 2:1-14

Agre AP, Badara G, Adjatin A, Dansi A, Bathacharjee R, Rabbi IY, Dansi M, Gedil M (2016) Folk taxonomy and traditional management of Cassava (Manihot esculenta Crantz) Diversity in Southern and Central Benin. Int J Innov Sci Res 20:500-515

Andrade EKV, Andrade Júnior VC, Laia ML, Fernandes JSC, Oliveira AJM, Azevedo AM (2017) Genetic dissimilarity among sweet potato genotypes using morphological and molecular descriptors. Acta Sci Agron 39:447-455

Asare PA, Galyuon IKA, Sarfo JK, Tetteh JP (2011) Morphological and molecular based diversity studies of some Cassava (Manihot esculenta Crantz) Germplasm in Ghana. Afr J Biotech 10:13900-13908

Beeching JR, Marmey P, Gavalda MC, Noirot M, Haysom HR, Hughes MA, Charrier A (1993) An assessment of genetic diversity within a collection of cassava (Manihot esculenta Crantz) germplasm using molecular markers. Ann Bot 72:515-520

Benesi M (2005) Characterization of Malawian Cassava Germplasm for diversity, Starch extraction and its Native and modified properties. PhD thesis, Free State University, South Africa

Bradbury PJ, Zhang Z, Kroon DE, Casstevens TM, Ramdoss Y, Buckler ES (2007) TASSEL: software for association mapping of complex traits in diverse samples. Bioinformatics 23:2633-2635

CIAT (1975) Centro International de Agricultural Tropical (CIAT) Cali, Colombia. Annual Reports, 1974

Collard BCY, Jahufer MZZ, Brouwer JB, Pary ECK (2005) An introduction to markers, quantitative trait loci (QTL) mapping and marker-assisted selection for crop improvement: the basic concepts. Euphytica 142:169-196

da Silva LI, Filho PSV, da Costa TR, Domingos ML, GoncalvesVidigal MC (2015) Molecular characterization of traditional Assessions from the periurban region, Toledo, Western Parana, Southern Brazil. J Glob Biosci 4:1268-1278

Dellaporta SL, Wood J, Hicks JB (1983) A plant DNA mini preparation Version II. Plant Mol Biol Rep 1:19-21

Dixon AGO, Ngeve JM, Nukenine EN (2002) Genotype $\times$ environment effects on severity of cassava bacterial blight disease caused by Xanthomonas axonopolis pv. manihotis. Eur J Plant Pathol 108(8):763-770

Elias M, McKey D, Panaud O, Anstett MC, Robert T (2001) Traditional management of cassava morphological and genetic diversity by the Makushi Amerindians (Guyana, South America): perspectives for on-farm conservation of crop. Euphytica 120:143-157 
Elshire RJ, Glaubitz JC, Sun Q, Poland JA, Kawamoto K, Buckler ES, Mitchell ES (2011) A robust, simple genotyping-by-sequencing (GBS) approach for high diversity species. PLoS ONE 6:e19379

Ferri L, Perrin E, Campana S, Tabacchioni S, Taccetti G, Cocchi P, Ravenni N, Dalmastri C, Chiarini L, Bevivino A, Manno G, Mentasti M, Fani R (2010) Application of multiplex single nucleotide primer extension ( $\mathrm{mSNuPE}$ ) to the identification of bacteria: the Burkholderia cepacia complex case. J Microbiol Methods 80:251-256

Fregene M, Bernal A, Duque M, Dixon AGO, Tohme J (2000) AFLP analysis of African cassava (Manihot esculenta Crantz) germplasm resistant to the cassava mosaic disease (CMD). Theor Appl Genet 100:678-685

Fukuda WMG, Guevara CL (1998) Morphological and agronomic descriptors for the characterization of manioc (Manihot esculenta Crantz). Cruz das Almas: Embrapa Cassava and Fruticulture, Documents 78

Fukuda WMG, Guevara CL, Kawuk R, Ferguson ME (2010) Selected morphological and agronomic descriptors for the characterization of cassava. International Institute of Tropical Agriculture (IITA): Ibadan (Nigeria)

Grattapaglia D, Kirst M (2008) Eucalyptus applied genomics: from gene sequences to breeding tools. New Phytol 179:911-929

Hurtado P, Olsen KM, Buitrago C, Ospina C, Marin J, Durque M, de Vincente C, Wongtiem P, Wenzel P, Killian A, Adeleke M, Fregene M (2008) Comparison of simple sequence repeat. Plant Genet Resour 20:47-55

IITA (1974) Cassava annual report. IITA, Ibadan

IITA (1990) Annual report. International Institute of Tropical Agriculture, Ibadan

Kawuki R, Ferguson M, Labuschagne M, Herselman L, Kim DJ (2009) Identification, characterisation and application of single nucleotide polymorphisms for diversity assessment in cassava (Manihot esculenta Crantz). Mol Breed 23:669-684

Liu K, Muse SV (2005) Power marker: integrated analysis environment for genetic marker data. Bioinformatics 21:2128-2129

Mckey D, Emperaire L, Elias M, Pinton F, Robert T, Desmoulière S, Rival L (2001) Local management and regional dynamics of varietal diversity of cassava in the Amazon. Genet Sel Evol 33:S465-S490

Mezette TF, Blumer CG, Veasey EA (2013) Morphological and molecular diversity among cassava genotypes. Pesq Agropec Bras 5:510-518

Nassar NMA (2005) Cassava: some ecological and physiological aspects related to plant breeding. An article published online with Gene Conserve

Okogbenin E, Egesi CN, Olasanmi B, Ogundapo O, Kahya S, Hurtado P, Marin J, Akinbo O, Mba C, Gomez H, de Vicente C, Baiyeri S, Uguru M, Ewa F, Fregene M (2012) Molecular marker analysis and validation of resistance to cassava mosaic disease in elite cassava genotypes in Nigeria. Crop Sci 52:2576-2586

Park Y-J, Lee JK, Kim NS (2009) Simple sequence repeat polymorphisms (SSRPs) for evaluation of molecular diversity and germplasm classification of minor crops. Molecules $14: 4546-4569$

Pinton F, Emperaire L (2001) Cassava in the Brazilian Amazon: varietal diversity and market. Genet Sel Evol 33:S491-S512

Rabbi I, Hamblin M, Gedil M, Kulakow P, Ferguson M, Ikpan AS, Ly D, Jannink J-L (2014) Genetic mapping using genotyping-bysequencing in the clonally propagated cassava. Crop Sci 54:1384-1396

Raghu D, Senthil N, Saraswathi T, Raveendran M, Gnanam R, Venkatachalam R, Shanmugasundaram P, Mohan C (2007) Morphological and simple sequence repeats (SSR) based finger printing of South Indian cassava germplasm. Int J Integrat Biol $1: 141-148$

Richman MB (1988) A cautionary note concerning a commonly applied eigenanalysis procedure. Tellus 40B:50-58

Sánchez T, Salcedo E, Ceballos H, Dufour D, Mafla G, Morante N, Calle F, Perez JC, Debouck D, Jaramillo G, Moreno IX (2009) Screening of starch quality traits in Cassava (Manihot esculenta Crantz). Starch/Stärke 61:12-19

Scott GJ, Rosegrant MW, Ringler C (2000) Roots and tubers for the 21 st century: trends, projections, and policy options. No 31, 2020 vision discussion papers, International Food Policy Research Institute (IFPRI). https://econpapers.repec.org/paper/fpr2020dp/ 31.htm

Siqueira MVBM, Queiroz Silva JR, Brascan EA, Borges A, Pereira KJC, Pinto JG, Veasey EA (2009) Genetic characterization of cassava (Manihot esculenta) landraces in Brazil assessed with simple sequence repeats. Genet Mol Biol 32:104-110

Smykal P, Horacek J, Dostalova R, Hybl M (2008) Variety discrimination in pea (Pisum sativum L.) by molecular, biochemical and morphological markers. J Appl Genet 49:155-166

Souza DCL (2015) Molecular techniques for characterization and conservation of medicinal and aromatic plants: a review. Rev Bras Plantas Med 17:495-503

Temegne NC, Ajebesone FN, Kuate AF (2015) Influence of soil chemical composition on nutrient content and yield of cassava (Manihot esculenta Crantz, Euphorbiaceae) in two agro-ecological zones of Cameroon. Int J Biol Chem Sci 9:2776-2788

Yang J, Dong A, Peng Z (2011) Expression profiling of cassava storage roots reveals an active process of glycolysis/glyconeogenesis. J Integrat Plant Biol 53:193-211

Publisher's Note Springer Nature remains neutral with regard to jurisdictional claims in published maps and institutional affiliations. 